\title{
RESEARCH
}

Open Access

\section{ICT usage to enhance firms' business processes in Tanzania}

\author{
Kelefa Mwantimwa(i)
}

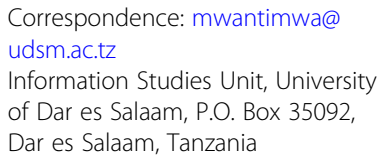

Correspondence: mwantimwa@ udsm.ac.tz

Information Studies Unit, University of Dar es Salaam, P.O. Box 35092

Dar es Salaam, Tanzania

\begin{abstract}
This study examined the usage of ICTs to enhance business processes in Tanzania. In particular, the study examined the types of ICTs deployed to enhance business processes and the processes they support, determinants of ICTs' viable usage, and barriers to their effective usage. Descriptive cross-sectional design using surveys was deployed to gather qualitative and quantitative data from 182 firms. Quantitative data were analysed with using SPSS IBM 22 to generate descriptive and inferential statistics results. Besides that, a thematic and content analysis was used to analyse qualitative data which was thereafter presented in narration form. The findings revealed that mobile phones, computers, the Internet and other network systems, and social media are perceived as important in boosting business efficiency related to material, product processing, management activities, service and marketing. The findings further disclose that financial capital has a multiplying effect on other ICTs' usage determinants such as knowledge and expertise, and ICT infrastructure investments. Regarding a firm's profile, the findings indicate that the size of a firm and its source of raw materials strongly predict its innovative usage of ICTs. The results also revealed the barriers to innovative usage of ICTs and suggest that for business processes to be meaningful, a balanced deployment of ICTs should be done with proper consideration of all enabling elements.
\end{abstract}

Keywords: ICTs, Social media, Usage, Firms, Business innovation, Business processes, Tanzania

\section{Introduction}

Any firm, regardless of its size, contributes a noticeable portion to the economic and social development of the country it operates in (Wolf, 2001). It is similarly a wellknown fact that the business sector contributes significantly to the Gross Domestic Product (GDP) of both developed and developing countries. One noteworthy fact is the change that has occurred in this sector, especially in terms of the drivers of this sector's growth. The tremendous increase of Information and Communication Technologies (ICTs) usage in the business sector has been vital in supporting the growth of the sector and acting as a good source of change (Gerguri-Rashiti, Ramadhani, Abazi-Alili, Leo-Paul, \& Ratten, 2015). Understandably, various scholars refer to these tools as drivers and enablers of, or cornerstones for the advancement of the business sector (Apiyo \& Kiarie, 2018; Billon, Marco, \& Lera-Lopez, 2017; Cirera, Lage, \& Sabetti, 2016; Grazzi \& Jung, 2015; Ssewanyama \& Busler, 2007). Similarly, the tools are considered as the bedrock for the sector's growth (United Republic of Tanzania [URT], 2016).

(c) The Author(s). 2019 Open Access This article is distributed under the terms of the Creative Commons Attribution 4.0 International License (http://creativecommons.org/licenses/by/4.0/), which permits unrestricted use, distribution, and reproduction in any medium, provided you give appropriate credit to the original author(s) and the source, provide a link to the Creative Commons license, and indicate if changes were made. 
On their part, Franco and Garcia (2017) found ICTs as a source of innovative solutions for the competitive development of businesses. In other words, ICTs are vital in efforts to create sustainable growth in firms. One of the unquestionable contributions is on the ways ICTs support business processes. Evidently, ICTs provide opportunities for coming up with enhanced and innovative ways of expanding markets and improving performance (Grazzi \& Jung, 2015). The adoption and application of ICTs increase opportunities to find innovative solutions for handling processes and product management, hence allowing businesses to thrive in competitive markets (Diaz-Chao, 2015; Franco \& Garcia, 2017; Kossai \& Piget, 2014; Organization for Economic Co-operation and Development [OECD], 2004). Additionally, aside from enhancing business processes such as the production of goods, ICTs also facilitate the usage of other technologies. Similarly, when looking at businesses in the sense of models, ICTs play a vital role in ensuring that all models [such as business-to-business (B2B), business-to-consumer (B2C) and supply chain management (SCM)] function properly (Cirera et al., 2016).

Recognising the value of ICTs, the government of Tanzania has introduced reforms and strategies to provide support for diverse initiatives aimed at boosting the usage of these tools in various sectors. For example, the government has since 2003 approved and implemented an ICT Policy framework which was then subjected to amendments in 2016. The policy stipulates that ICTs are a driving force for the realisation of socioeconomic growth in all sectors (URT, 2016). Among other things, the National ICT Policy 2016 intends to put in place measures and mechanisms to accelerate broadband penetration and access, strengthen ICT security and standardisation, enhance management and efficient utilisation of spectrum and other scarce ICT resources, promote business process outsourcing industry and enhance efficiency in e-service and business. Besides the policy, the government's commitment to this cause is evident in its investment of resources in ICT-related projects such as the installation of a broadband infrastructure to improve communication services in the country. Such initiatives are made as part of efforts to accelerate poverty reduction and achieve National Strategy for Economic Growth and Poverty Reduction (NSEGPR) and National Development Vision 2025 objectives (URT, 2005).

However, despite the government's initiatives and reforms to promote the adoption and application of ICTs in all sectors, slow acceptance and implementation of these tools have been registered across the business firms. For example, the usage of software has been found to be insignificant in all types of business firms regardless of their sizes. Divergently, the usage of Internet services to foster business performance has been recorded to be low in small size firms as compared to medium and large firms. Regarding the usage of computers, firms of all sizes have been found to deploy these technologies to support their businesses (Cirera et al., 2016).

Table 1 shows that Tanzania is lagging behind compared to Kenya and other sub-Saharan countries in terms of ICT diffusion and uptake in business (Cirera et al., 2016). To date, there are very few studies (Cirera et al., 2016; Diyamett, Makundi and Mwantimwa, 2012) that clearly disclose the status of ICT usage to support innovation in manufacturing firms. In addition, the extent to which ICTs contribute towards business processes is still under debate and the question about the extent to which these tools can boost productivity remains unanswered. The lack of clarity on this matter is an apparent need for more empirical studies examining the importance of ICTs, especially in 
Table 1 ICTs' usage status by selected countries in Africa

\begin{tabular}{lllllllll}
\hline \multirow{2}{*}{ Types of firms } & ICTs & \multicolumn{5}{c}{ ICT (i.e., computer, Internet and software) usage by selected countries (\%) } \\
\cline { 3 - 8 } & & Ghana & DRC & Tanzania & Uganda & Zambia & Kenya & Average \\
\hline \multirow{2}{*}{ Small } & Computer & 57.3 & 48.8 & 34.3 & 60.0 & 67.4 & 81.5 & 58.2 \\
& Software & 7.0 & 28.2 & 7.9 & 14.0 & 22.1 & 22.2 & 17.1 \\
\cline { 3 - 8 } Medium & Internet & 43.8 & 20.9 & 18.0 & 21.3 & 44.2 & 64.4 & 35.5 \\
& Computer & 89.7 & 74.4 & 59.6 & 35.3 & 67.5 & 96.8 & 70.5 \\
& Software & 17.9 & 37.8 & 16.6 & 14.2 & 24.2 & 39.7 & 25.4 \\
& Internet & 83.0 & 58.7 & 34.2 & 19.3 & 56.4 & 83.1 & 55.8 \\
\multirow{4}{*}{ Large } & Computer & 98.6 & 94.1 & 69.9 & 89.6 & 100 & 100 & 91.9 \\
& Software & 25.6 & 61.1 & 22.0 & 21.0 & 58.5 & 46.1 & 38.4 \\
& Internet & 95.5 & 63.7 & 42.9 & 80.4 & 93.3 & 87.6 & 77.2
\end{tabular}

Source: Cirera et al., 2016

developing counties where the need for productivity growth is more acute (Cirera et al., 2016). Additionally, studies on the usage of ICTs to enhance business process have not been given the same weight as those on performance and challenges (Franco \& Garcia, 2017). This study was therefore conducted to examine the usage of ICT to enhance business processes in firms. Specifically, the study identified types of ICTs used to enhance business processes in firms as follows: examined the types of processes ICTs support, explored the determinants of ICT adoption and usage to support business process and examined barriers that deter the usage of ICTs to enhance business efficiency in firms in Tanzania.

\section{Literature}

\section{ICTs and their support for business processes}

The types of ICTs used to support business processes vary from one firm to another. While some of the firms are deploying advanced ICT tools, others are using basic ones. Basically, the firms deploy computers, networks, the Internet and various software products for business processes (Cirera et al., 2016; Gerguri-Rashiti et al., 2015; Hagsten \& Kotnik, 2017). It is a confirmed fact that ICTs such as personal computers and the Internet are widespread in firms of different sizes (OECD, 2004). Surprisingly, few of the reviewed studies have reported mobile phones as tools for enhancing firms' business processes and innovation (Krone, Schumacher, \& Dannenberg, 2014). In fact, mobile phones are multi-purpose communication tools, which facilitate various firms' business processes (Mwantimwa, 2019).

The value of ICTs in business avenues can be likened to that of engine oil in supporting and maintaining motion. Like an engine, ICTs' usage boosts a firm's growth and helps in the transformation of business models (Barret, Davidson, Prabhu, \& Vargo, 2015). Besides productivity, ICTs are a key element of the promotion of diversification of business processes (Diaz-Chao, 2015; Jorgenson, Ho and Samuels, 2011). Understandably, the usage of ICTs in business activities is found to have an additional positive effect on diverse business activities such as those process and organisational related (Grazzi \& Jung, 2015). In fact, a positive and significant impact of ICT on firms' business can be measured along the dimensions of a firm's products, processes and 
organisational practices (Barret et al., 2015; Cirera et al., 2016; Eze \& Chinedu-Eze, 2018). For instance, the impact of the usage of ICTs in the enhancement of business processes in firms manifests itself in product development, and marketing and process restructuring (Bartelsman, Hasten, \& Polder, 2017; Billon et al., 2017; Gerguri-Rashiti et al., 2015; Idota, Ueki, Bunno, Shinohara, \& Tsuji, 2014; Wolf, 2001). Apart from the impact on the product process, technology has brought new opportunities for business innovations (Barret et al., 2015; Eze \& Chinedu-Eze, 2018). On a different note, the constant technological advancements have led to a profound change in markets, characterised by increased competition (Franco \& Garcia, 2017). With the help of ICTs, businesses have been offered ways to diversify their markets particularly through the Internet where buying and selling of goods and services are done in addition to the acquisition of ideas for new designs of products (Gerguri-Rashiti et al., 2015).

With regard to business models, the usage of ICT has brought considerable changes to the business-to-business (B2B), business-to-consumers (B2C), e-business, and supply chain management (SCM) models (Idota et al., 2014). Social media platforms in particular are becoming more important in the enhancement of business processes (Papa, Santoro, Tiraben, \& Monge, 2018). Overall, OECD (2004), and OECD and Eurostat (2005) presented examples of the benefits of ICTs' usage across a wide range of intrafirm business processes which in summary include the support provided to products and services development, marketing diversification and communication. For instance, ICTs are used as tools for receiving customers' feedback, promoting products and services, making purchases, documentation, customer data processing, organising incoming orders, preparing invoices, and creating and managing customer databases. From this, it can be seen that ICTs also facilitate customer service delivery, a notion also supported by Michael (2015) who argued that these tools are at the centre of today's customer services. Likewise, Southern and Tilley (2000) also highlighted the role of ICTs in customer services by pointing out their importance in all organisational activities and process, and their enhancement of communication and working patterns all of which produce better services for customers. In all, ICTs support designing and redesigning of products, packaging, improvement of services delivery and diversification of marketing. Divergently, Arendt and Grabowski (2018) argued out that despite the value of ICTs in supporting business processes, it would not be a good idea for any business to consider them as the only area to focus on, hence disregarding other innovation factors such as organisational culture.

\section{Determinants of ICT adoption and usage for business processes}

Factors that determine the adoption and usage of ICTs in business processes are well documented. Numerous studies (see for example, Cirera et al., 2016; Gerguri-Rashiti et al., 2015; Grazzi \& Jung, 2015) have noted that the size, location and age of a firm are important determinants of ICT adoption and usage for business. Grazzi and Jung (2015) revealed that larger, older, export-oriented and urban-based firms are more likely to adopt ICTs than those that are not. The authors further elaborated that the location of a firm becomes less relevant to customers after the adoption of ICTs since customer-business communication becomes easier. On the same note, Gerguri-Rashiti et al. (2015) suggested that the size of a firm predicts the likeness of ICT adoption and 
usage and explains the kinds of innovation to be expected. The authors argued that based on the findings of their study, it is clear that bigger firms in transition economies tend to carry out more innovation activities than smaller ones although some of them do not. Aside from that, the authors disclosed that larger firms in concentrated markets are more advantaged with regard to the deployment of ICTs for business processes. To confirm this, OECD (2004) found that smaller businesses are slower in adopting all kinds of technologies as compared to bigger ones as evident in the wide usage of the Internet in bigger firms. This observation brings more confusion than clarity considering the fact that the usage of some technologies particularly mobile phones is on a dramatic rise in all kinds and sizes of firms. Apart from the size of a firm, the author found the availability of incentives, business models used, ICT usage knowledge and other technological capabilities, appropriateness of business environment for ICT uptake and e-business, availability of markets and the expected profit as principal drivers of ICTs' usage for business. Apart from size, the age, location, and nature of a firm's ownership are the other factors that determine the usage of ICTs for productivity and innovation in business processes.

Apart from the aforementioned predictors, literature suggested that knowledge and skill intensive (Billon et al., 2017; Cirera et al., 2016; Grazzi \& Jung, 2015; Papa et al., 2018; Tahir \& Sam, 2010), less financial constrained, and foreign-owned firms and those that operate under higher degrees of competition (Cirera et al., 2016; Ssewanyama \& Busler, 2007) are more likely to use ICTs for business processes. This was partly evident in Uganda where large- and medium-sized firms owned by foreigners were found to deploy Internet services more effectively than indigenous ones. The main contributing factors to such effectiveness in Internet service deployment included the presence of competent managers, high-skilled workforce, and advanced business practices (Ssewanyama \& Busler, 2007). Arendt and Grabowski (2018) validated part of the Ugandan scenario by arguing that human capital positively influences the adoption and usage of technologies as confirmed by their study conducted in Poland. Similarly, Franco and Garcia (2017) revealed that the presence of networking and other ICT experts are important predictors of ICTs' usage although their influence has been reported to be not significant enough.

On the other hand, the frequency and extent of experience of ICT usage have been found to significantly contribute to the increase of innovation capabilities in firms (Tahir \& Sam, 2010) while the quality of ICTs used explains the kinds of innovation to expect (Michael, 2015). Similarly, results from a study by Billon et al. (2017) disclosed that the number of highly educated employees a business has explains the extent of ICT usage to support business in European regions. However, the authors have also reported that employees' ages correlate with the level of ICT skills and knowledge in a way that the older an individual is, the lower the skills and knowledge he or she will have. In brief, the details presented under this section signify that financial stability alone cannot effectively predict the usage of technology to enhance business efficiency, hence the need to recognise the value of other factors such as skills and knowledge.

\section{Barriers to ICT usage for business processes in firms}

According to Cirera et al. (2016), variations in the usage of ICTs for business processes among firms are not only present among developing countries. The presence of these 
differences across all nations is due to the fact that they are associated with various challenges faced by individual firms which include the insufficiency of resources and bargaining power among small firms. As a result of such challenges, majority of small firms are not investing much in the acquisition of ICTs and usage training (GerguriRashiti et al., 2015; Hadjimanolis, 2000). In other words, financial constraints deter the accessibility of ICTs and limit capacity building among firms. In fact, low ICTs' savvy undermines firms' innovativeness in areas such as marketing, processing, organisation, and product development and improvement (Mwantimwa, 2019).

Apart from that, such low diffusion and usage of ICTs among firms can also be attributed to unfavourable national political environments and poor governance. Issues such as long custom procedures on imported equipment and high costs of quality of ICT equipment are some of the factors resulting from the nature of government policies that hinder effective adoption and usage of these tools among firms (Michael, 2015). For instance, expenses associated with acquiring and managing quality hardware, software and qualified staff and the taxes levied on them, coupled with Internet security issues, high VAT and connection costs have been found to limit the adoption and usage of ICTs in Uganda (Ssewanyama \& Busler, 2007). Besides that, the lack of incentives, unclear returns, transaction security threats, lack of trust, inadequate knowledge and skills, and market failures also play a role in slowing down the adoption and usage of ICTs for innovation (Mwantimwa, 2018; OECD, 2004). Consequently, micro-firms are very reluctant and slow to adopt ICTs and often unable to benefit from them. In summary, everything points to the insufficiency of financial, technical and management resources and the lack of skills and knowledge needed to use such tools among microfirms (Franco \& Garcia, 2017).

\section{Literature gaps}

There are numerous studies (e.g., Arendt \& Grabowski, 2018; Barret et al., 2015; Bartelsman et al., 2017; Billon et al., 2017; Franco \& Garcia, 2017; Gerguri-Rashiti et al., 2015; Grazzi \& Jung, 2015; Idota et al., 2014; Tahir \& Sam, 2010) that have been conducted in other parts of the world with a focus on ICTs' usage to support business processes in a diversity of firms. However, such studies and particularly those that provide more insight on ICTs' usage to support firms' innovation are few (e.g., Cirera et al., 2016; Diyamett, Makundi, \& Mwantimwa, 2012). There is a dearth of knowledge on studies that present comparative analysis across firms, and Tanzania is not spared. In addition, little is known on the types of ICTs used to support diverse business processes, the perceived importance of these tools in enhancing business, determinants of their usage for innovation and barriers of their effective usage for business process. This study on ICTs' usage to support firms' business processes contributes to filling these gaps.

\section{Methodology}

\section{Study design and approach}

This study deployed a descriptive and a cross-sectional research design and combined qualitative and quantitative approaches to gather primary data. Although a descriptive design tends to be quantitative in nature, it also contains qualitative aspects (see 
Sreejesh, Sanjay, \& Anusree, 2014). In short, the design has the ability of obtaining more information on characteristics within a particular research problem by providing a picture of practices as they naturally happen (Burns \& Grove, 2011; Jackson, 2008). With regard to this study, the design was important in the examination of the usage of ICTs to support firms' innovations by guiding the collection of data on firms' profiles and types of ICTs used and the innovations they support. While data on such aspects were collected through a quantitative approach, data on opinions and perceptions of the usefulness of ICTs in supporting different kinds of innovations were collected through a qualitative approach in a cross-sectional design. The cross-sectional design allowed the researcher to study different variables from each individual at a single point of time. Basically, under this approach, a variety of elements can be studied in a short period, hence allowing the researcher to collect data from all the participating firms within a short period of time (Mwantimwa, 2012).

\section{Study setting and sampling}

This study was conducted during the 41st Dar es Salaam International Trade Fair (DITF) held from the 28th of June to the 13th of July 2017. The participants of this study came from various production, processing and service firms which participated in the trade fair. The event was an appropriate study setting because it attracts and brings to one place different firms regardless of their sizes, nature and location by offering them a way to market their services and products to local and international audiences. Besides that, the DITF provides opportunities for various firms to meet under the same roof or premise, hence facilitating their connection of production and marketing efforts, information sharing, and the acquisition and exchanging of innovative ideas and knowledge (Rutageruka, 2017). As a result, the event was a very appropriate setting for this study because it made the collection of data more economical and convenient. In addition, the event helped the researcher in getting a more appropriate sample for the study. Given the impossibility of studying the whole population and the complexity of studying all the elements of a population, sampling is quite important (Franco \& Garcia, 2017). Accordingly, this study employed stratified-random sampling to draw its sample from a total of about 2500 multi-national (operating in Tanzania) and local exhibitors participated in the 41st DITF (TANTRADE, 2017). To come up with a representative sample (i.e. 230 exhibitors), the following procedures were taken into consideration:

i. The firms were put in 15 strata based on the pavilions they were showcasing their services and products;

ii. From each stratum, the multi-national (operating in Tanzania) and local exhibitors were randomly selected for the purpose of enhancing representation.

In all, to get a representative sample, a combination of stratified and simple random sampling mechanisms was used. The procedure involves subdividing the population into subpopulations and then randomly selecting a sample from the subpopulations.

\section{Research methods, instruments and protocol}

To meet the requirements of the objective of the study which was gauging the usage of ICTs in firms' innovations, cross-sectional surveys were used to gather primary data 
from selected firms. Under the surveys, data were collected using questionnaires and interviews. A total of 230 questionnaires were distributed to the selected firms' representatives out of whom 182 were completed and returned representing a $79.1 \%$ response rate. These self-administered questionnaires comprised open- and close-ended questions and employed ordinal and nominal measurement scales. The questionnaire used was divided into different sections where section 'A' was about firms' profiles while section ' $\mathrm{B}$ ' was about firms' ownership of ICTs, their usage frequency, perceived importance in supporting innovations, determinants of their usage for innovation and usage challenges. The instrument was distributed by four research assistants.

On the other hand, semi-structured key informant interviews were conducted face to face. Besides the surveys, an observation method was used to note different types of ICT firms used to showcase their products and services. An observation checklist was the instrument used to guide the researcher in the observing process. Accordingly, secondary data was collected through documentary review under which various documents including the National Information and Communication Policy of Tanzania [2016] were consulted.

\section{Reliability test of instruments}

Besides a pilot test involving 9 firms that were conducted on the first day of the DITF, Cronbach's coefficient alpha values for variables were performed to measure the internal consistency of the instruments. Table 2 summarises the alpha outputs for the reliability scales:

Referring to Cronbach's Alpha, values vary between 0 and 1 where those closer to 1 indicate greater internal consistency while those that are closer to 0 entail low consistency. It is also important to note that an alpha value above 0.70 is more recommended (Franco \& Garcia, 2017). Basing on this measure, all the tested variables were found to have a great internal consistency since their alpha values were $>0.70$, hence indicating that the instruments were reliable.

\section{Data analysis}

During the analysis process, quantitative and qualitative data were organised categorically and chronologically, reviewed repeatedly and continually coded and analysed. Quantitative data were analysed using Statistical Products for Service Solutions (SPSS) [IBM 22] to generate descriptive and inferential statistical results. Descriptive statistics (e.g. frequency and percentage) were employed to see differences in different variables while inferential statistics were used to analyse the relationship of the variables. For

Table 2 Reliability test of instruments

\begin{tabular}{lll}
\hline Test variables & No. of items & Alpha \\
\hline Firms' profile & 8 & .821 \\
Types of ICTs & 10 & .906 \\
Potential ICTS & 5 & .754 \\
Usage of ICTs on innovation & 10 & .869 \\
Determinants of ICT usage for innovation & 10 & .882 \\
Challenges of ICT usage & 6 & .749 \\
\hline
\end{tabular}


example, multiple linear regression analysis was used to gauge the influence of firms' profiles on the innovative application of ICTs. On the other hand, the recorded interviews and participants' recorded information were transcribed. Accordingly, a thematic and content analysis was used to analyse qualitative data which was thereafter presented in narration form.

\section{Results}

\section{Firms' profile}

Quantitative results from 182 firms are presented and interpreted in this section. In particular, the section discloses the participating firms' profiles, the kinds of ICTs they own, the frequency of their usage and challenges facing in doing so in their product designing, processing, management and services provision. Descriptive statistics analysis was performed to reveal the composition of the participating firms' based on their profiles. Table 3 presents the firms' profiles:

Basically, the results indicate that majority of the firms were established before 2010 while a few of them were established after that which implies that most of them have considerable experience in doing business and providing services. On the types of business, the results indicate that the firms were involved in manufacturing, processing,

Table 3 Firms' profile

\begin{tabular}{|c|c|c|c|}
\hline \multirow[t]{2}{*}{ Firms' profile $(n=182)$} & & \multicolumn{2}{|c|}{ Descriptive statistics } \\
\hline & & Frequency & Percent \\
\hline \multirow[t]{3}{*}{ Year of establishment } & $<2000$ & 56 & 30.8 \\
\hline & $2001-2010$ & 78 & 42.9 \\
\hline & $>2011$ & 48 & 26.4 \\
\hline \multirow[t]{5}{*}{ Business types } & Manufacturing & 59 & 32.4 \\
\hline & Processing & 33 & 18.1 \\
\hline & Exporting & 10 & 5.5 \\
\hline & Importing & 26 & 14.3 \\
\hline & Services & 54 & 29.7 \\
\hline \multirow[t]{3}{*}{ Size of firms } & Small & 41 & 22.5 \\
\hline & Medium & 22 & 12.1 \\
\hline & Large & 119 & 65.4 \\
\hline \multirow[t]{2}{*}{ Ownership } & Private & 143 & 78.6 \\
\hline & State-run & 39 & 21.4 \\
\hline \multirow[t]{2}{*}{ Origin } & Local & 133 & 73.1 \\
\hline & Foreign & 49 & 26.9 \\
\hline \multirow[t]{3}{*}{ Sources of materials } & Foreign & 87 & 47.8 \\
\hline & Local & 35 & 19.2 \\
\hline & Both & 60 & 33.0 \\
\hline \multirow[t]{2}{*}{ Markets } & Domestic & 125 & 68.7 \\
\hline & Domestic and foreign & 57 & 31.3 \\
\hline \multirow[t]{3}{*}{ Headquarter } & Dar es Salaam & 147 & 80.8 \\
\hline & Outside DSM & 28 & 15.4 \\
\hline & Outside Tanzania & 7 & 3.8 \\
\hline
\end{tabular}

Source: Field Data, 2017 
exporting, importing products and providing services. It is worth noting that a moderate percentage of the firms were involved in manufacturing and service provision while even fewer were involved in exporting, importing and product processing. Regarding the sizes of the firms, a significant percentage $(65.4 \%)$ of them were large firms while the remaining percentage included small- and medium-sized ones. This representation can be attributed to the fact that large firms can more easily afford the trade fair's participation fees than their smaller counterparts.

With regard to ownership, majority (78.6\%) of the firms were private owned. This is easy to comprehend because the government is currently not actively involved in investing through creating its own firms. On a similar note, a noticeable percentage of the firms were local while a smaller percentage of them were originally from outside the country. In terms of raw material sources, the results reveal that a moderate percentage $(47.8 \%)$ of the firms imported their materials while $33 \%$ of them used both local and foreign materials. The results further reveal that most of the firms (68.7\%) depend on domestic markets to sell their products and deliver services. With respect to their locations, majority (80.8\%) of the firms' headquarters were situated in Dar es Salaam while a few of them were situated outside Dar es Salaam and Tanzania.

\section{Facilities ownership, Internet subscription and frequency of ICTs' usage}

The firms' representatives were asked to mention the kinds of ICTs owned by their firms and identify those useful in supporting diverse business processes. The results obtained indicate that the firms owned different kinds of ICTs and subscribed to Internet services. However, the results also reveal that just a few of the ICTs owned by the firms were found useful in supporting business processes. Table 4 summarises the kinds ICTs owned by the firms that participated in the study and the frequency of their usage and shows if they were subscribed to Internet services or not:

In general, the results reveal that all firms indicated that they own different kinds of ICT facilities. Specifically, most of the firms mentioned that they own mobile phones (100\%), computers $(81.9 \%)$, EFD machine $(73.6 \%)$, landline telephones $(65.4 \%)$, photocopier machines $(62.6 \%)$ and websites $(47.3 \%)$. In addition, the results revealed that a moderate percentage $(42.3 \%)$ of the firms have subscribed to Internet services while only a small percentage of them have barometric machines. In all, the results suggest that majority of larger firms owned ICTs and subscribed to Internet services as compared to small- and medium-sized ones. Apart from that, the findings indicate that mobile phones are the most frequently used tools by all the firms involved in this study. The chi-square test results of Pearson performed revealed an insignificant difference in the ownership and usage of mobile phones and barometric machines $(P$ value $>.05)$ while for the other kinds of ICTs, the difference was statistically significant $(P$ value $<.05)$. On the usefulness of ICTs, a statistically significant difference $(P$ value $<.05)$ was found on the usefulness of computer, Internet services, software and websites.

\section{ICT usage in business processes}

Regarding the frequency of ICT usage, a significant percentage (72\%) of the firms revealed that they frequently use ICTs to support their different kinds of innovations. The results further show that the usage of the ICTs to business processes in the 
Table 4 ICT ownership, Internet subscription and usefulness of ICTs in business processes

\begin{tabular}{|c|c|c|c|c|c|c|}
\hline \multicolumn{2}{|c|}{ ICT ownership and frequency of use $(n=182)$} & \multicolumn{3}{|c|}{ Types of firms } & \multirow[t]{2}{*}{ Total } & \multirow[t]{2}{*}{$P$ value } \\
\hline & & Small & Medium & Large & & \\
\hline \multirow{10}{*}{$\begin{array}{l}\text { ICT facility ownership and } \\
\text { Internet subscription }\end{array}$} & Computers & $12(29.2 \%)$ & $18(81.8 \%)$ & $119(100 \%)$ & $149(81.9 \%)$ & .000 \\
\hline & Mobile phone & $41(100 \%)$ & $22(100 \%)$ & $119(100 \%)$ & $182(100 \%)$ & .948 \\
\hline & Landline telephone & $8(19.5 \%)$ & $14(63.6 \%)$ & $97(81.5 \%)$ & $119(65.4 \%)$ & .000 \\
\hline & Photocopier & $4(9.8 \%)$ & $10(45.5 \%)$ & $100(84 \%)$ & $114(62.6 \%)$ & .000 \\
\hline & Printer & $16(39.0 \%)$ & $14(63.6 \%)$ & $98(82.4 \%)$ & $128(70.3 \%)$ & .000 \\
\hline & Scanner & $8(19.5 \%)$ & $6(27.3 \%)$ & $45(37.8 .0 \%)$ & $59(32.4 \%)$ & .072 \\
\hline & EFD & $19(46.3 \%)$ & $17(77.3 \%)$ & $98(82.4 \%)$ & $134(73.6 \%)$ & .014 \\
\hline & Barometric & $0(0.0 \%)$ & $2(9.1 \%)$ & $14(11.8 \%)$ & $16(8.8 \%)$ & .785 \\
\hline & Website & $9(22.0 \%)$ & $8(36.4 \%)$ & 69 (58.0\%) & $86(47.3 \%)$ & .004 \\
\hline & Internet subscription & $5(12.2 \%)$ & $10(45.5 \%)$ & $62(52.1 \%)$ & 77 (42.3\%) & .000 \\
\hline \multirow{5}{*}{$\begin{array}{l}\text { Useful ICTs to support } \\
\text { business processes }\end{array}$} & Computers & 9 (22.0\%) & $14(63.6 \%)$ & 96 (80.7\%) & $119(65.4 \%)$ & .022 \\
\hline & Mobile phone & 34 (82.9\%) & $18(81.8 \%)$ & $61(51.3 \%)$ & $113(62.1 \%)$ & .643 \\
\hline & Internet services & $16(39.0 \%)$ & $14(63.6 \%)$ & 74 (62.2\%) & 104(57.1\%) & .005 \\
\hline & Software & $8(19.5 \%)$ & $13(59.1 \%)$ & $50(42 \%)$ & 71 (39\%) & .000 \\
\hline & Website & $1(2.4 \%)$ & $6(27.3 \%)$ & $54(45.4 \%)$ & $61(33.5 \%)$ & .003 \\
\hline
\end{tabular}

Source: Field Data, 2017

surveyed firms varies. Table 5 summarises the kinds of business processes boosted by the application of ICTs:

Basing on these results, it can be seen that ICTs support various business processes in firms. Majority (87.4\%) of the representatives of the firms pointed out that the facilities are deployed for communicating with suppliers and clients while $73.6 \%$ said they are used to make money transactions, and $71.9 \%$ said they are used in the processing of orders from suppliers and clients. In addition, $60.9 \%$ of the firms have been reported to use the tools to create databases for managing their human resources and other assets, $60.4 \%$ indicated that they use them to manage records and data while $46.2 \%$ use them to promote products and services, $36.8 \%$ use them to process products and services and $32.4 \%$ use them to receive customers' feedback and prepare invoices. On the other hand, the usage of ICTs for security purposes was mentioned by the lowest number of firm representatives.

Pearsons' chi-square test performed reveals insignificant differences existing on the usage of ICTs for promoting and marketing products and services, receiving customers' feedback, making financial transactions, communicating with clients and vendors and strengthening security across the firms since $P$ value is $>.05$. On a different note, a statistically significant difference has been found on the usage of ICTs for processing orders, management, managing records and data, creation of invoices, promotion of products and services, designing new products and services since $P$ value is $<.05$. On the whole, variations have been observed in the usage of ICTs for different innovative activities across firms of different sizes. In short, the results reveal that the usage of ICTs for business processes in small enterprises is low compared to medium and large ones. The quantitative results tally with those from qualitative in different aspects. For example, one of the key informants (i.e. no.7) strongly expressed the value of ICTs as follows: 
Table 5 ICT usage in firms' business processes

\begin{tabular}{|c|c|c|c|c|c|}
\hline \multirow[t]{2}{*}{ ICT usage on innovation $(n=182)$} & \multicolumn{3}{|c|}{ Types of firms } & \multirow[t]{2}{*}{ Total } & \multirow[t]{2}{*}{ Sig. } \\
\hline & Small & Medium & Large & & \\
\hline \multirow[t]{2}{*}{ ICTs are used to promote and market products and services } & 14 & 9 & 61 & 84 & .585 \\
\hline & $34.1 \%$ & $40.9 \%$ & $51.3 \%$ & $46.2 \%$ & \\
\hline \multirow[t]{2}{*}{ ICTs are deployed to process orders from suppliers and clients } & 19 & 14 & 98 & 131 & .013 \\
\hline & $46.3 \%$ & $63.6 \%$ & $82.4 \%$ & $71.9 \%$ & \\
\hline \multirow[t]{2}{*}{ We created different management database } & 8 & 10 & 93 & 111 & .000 \\
\hline & $19.5 \%$ & $45.5 \%$ & $78.2 \%$ & $60.9 \%$ & \\
\hline \multirow[t]{2}{*}{ ICTs are used for process products and design new services } & 6 & 9 & 52 & 67 & .046 \\
\hline & $14.6 \%$ & $40.9 \%$ & $43.7 \%$ & $36.8 \%$ & \\
\hline \multirow[t]{2}{*}{ ICTs are used to communicate with our suppliers and clients } & 29 & 13 & 117 & 159 & .061 \\
\hline & $70.7 \%$ & $59.1 \%$ & $98.3 \%$ & $87.4 \%$ & \\
\hline \multirow[t]{2}{*}{ We are making our financial transactions by using ICTs } & 34 & 16 & 84 & 134 & .723 \\
\hline & $82.9 \%$ & $72.7 \%$ & $70.6 \%$ & $73.6 \%$ & \\
\hline \multirow[t]{2}{*}{ We use ICTs for strengthening and handling security issues } & 3 & 5 & 36 & 44 & .057 \\
\hline & $7.3 \%$ & $22.7 \%$ & $30.3 \%$ & $24.2 \%$ & \\
\hline \multirow[t]{2}{*}{ We use ICTs to receive customer's feedback } & 11 & 7 & 41 & 59 & .071 \\
\hline & $26.8 \%$ & $31.8 \%$ & $34.5 \%$ & $32.4 \%$ & \\
\hline \multirow[t]{2}{*}{ We use ICTs to manage our records and data } & 9 & 12 & 89 & 110 & .002 \\
\hline & $22.0 \%$ & $54.5 \%$ & $74.8 \%$ & $60.4 \%$ & \\
\hline \multirow[t]{2}{*}{ ICTs are used to prepare invoices } & 5 & 8 & 46 & 59 & .045 \\
\hline & $12.4 \%$ & $36.4 \%$ & $38.7 \%$ & $32.4 \%$ & \\
\hline
\end{tabular}

Source: Field Data, 2017

The introduction of computers and mobile devices has changed the model of doing our business. With the help of these technologies we now have clients from everywhere. Our reach now is beyond our usual geographic confinement. We can now sell our products online as well as order and acquire materials online. In simple terms, these computerised technologies and the internet are helping us increase our innovativeness and competitiveness. We always feel the need to move along with these technologies to remain a vibrant firm [gender, male; age 48; designation, supervisor; type of firm, manufacturing; town, Dar es Salaam].

In her words, key informant no.9 said that:

In our firm we frequently use social media to promote our products. Our intensification of the usage of platforms such as Facebook, WhatsApp, Twitter, and more recently Instagram has come out of the realisation that majority of our current and potential customers are their users. These tools make it easier for our marketing efforts to reach our customers. With the interactive nature of these tools, we now also receive many enquiries from our customers about our new products. In short, our usage of social media is helping us cut down on costs we used to incur from promoting our products on TVs and radio [gender, female; age, 39; designation, marketing manager; business type, product processing; town, Dar es Salaam]. 
Apart from that, another way ICTs positively contribute to firms' performance was explained by respondent no. 5 as follows:

Our IT experts have created computerised databases for managing company assets, clients' contact details and employees' profiles. The databases have been created using Microsoft Access and we can access them online or offline hence making important data more accessible. For example, even though I am here (away from office), I can retrieve contact details of our clients who have visited and bought our products. We use the same contacts to disseminate information about our new products and or discounts, and in our other communication with them to build and maintain better relationships [gender, male; age, 52; designation, manager; business type, manufacturing; town, Arusha].

On a similar note, key informant no. 13 opined that:

Our way of communicating has changed since we have started using emails and mobile phones. With the help of emails and mobile phones, it is possible to create and distribute a message to multiple clients at once. In addition, sharing of information about our services and products has radically become simpler because of the usage of mechanisms such as emailing, text messaging, and social media messaging. These days, in just a short period of time a large community of our clients can be made aware of our new products and services [gender, male; age, 44; designation, director; business type, service company; town, Dar es Salaam]

Regarding the creation of marketing tools, key informant $t$ no. 8 discloses the following:

Marketing tools such as flyers and business cards are now created by our own staff in the marketing department as opposed to our previous dependence on outsourcing them from other firms which used to cost us a lot of money. The firm is now spending less on marketing our products. This is also contributed to by the usage of social media in the promotion of our products. We really appreciate the business processes that ICTs are supporting in our firm [gender, female; age, 35; designation, managing director; business type, manufacturing; town, Tanga].

On a different note, key informant no. 15 has the following to share on the role of ICTs:

Considering that our firm mainly depends on imported raw materials, ICTs have helped us by lessening the difficulties usually faced in the processing of orders for such materials. With the help of the Internet, we now order raw materials directly from vendors' databases. Similarly, the transfer of money to vendors has become easier with the presence of ICTs. In all, the technologies offer opportunities to finish transactions within a short time by lessening the amount of time used to process orders, import and export goods, and make transactions [gender, female; age, 41; designation, manager; type of business, importing products; town, Dar es Salaam]. 
Another key informant testified that:

When I want to come with a design of a product I first search for different designs on the Internet. I spend much time learning so I can come up with best designs. With the presence of various search engines, I am now able to search for and look at various presentations (e.g. images) of ideas. For example, I can search house images on Google and use what I get to update my architectural skills and knowledge. Besides that, advanced open source software (OSS) packages for designing buildings are now readily available for use and customisation hence sparing architects from the need to spend a lot of money to acquire software [gender, male; age, 39; designation, director; type of business, service; town, Dar es Salaam].

In all, quantitative and qualitative results clearly inform that ICTs support various business processes in firms. The technologies are without doubt offering a significant contribution to promotion activities. Additionally, the tools have been reported to foster the designing of quality products and services and support the processing of orders from and to the clients and vendors, respectively. Furthermore, the findings also highlight the support ICTs offer to the management of human resources and clients. Undeniably, ICTs are important elements for fostering business efficiency and increasing competiveness and performance.

\section{Determinants of ICTs' usage for business processes}

A question on the determinants of ICTs' usage in firms' business process was important in the identification of the factors that predict the usage of these tools to support business in the selected firms that participated in DITF of 2017. The obtained results reveal a number of predictors as Table 6 presents:

In all, the results signify that the availability of ICT hardware (94.5\%), Internet (87.9\%), software (65.4\%), knowledge investments (56.4\%) and networking are the more prominent predictors of the usage of ICTs to support business processes in the selected firms. These determinants appear to be followed in prominence by the nature and size of a firm (48.9\%) and awareness of different kinds of ICTs (37.4\%).

Table 6 Determinants of ICT usage to enhances business processes

\begin{tabular}{llc}
\hline Determinants of ICT usage for innovation $(n=182)$ & Frequency & Percent \\
\hline ICT hardware & 172 & 94.5 \\
Internet & 160 & 87.9 \\
ICT software & 119 & 65.4 \\
Knowledge investments & 102 & 56.4 \\
Networking & 94 & 51.6 \\
Nature and size of the firms & 89 & 48.9 \\
Awareness on the kinds of ICTs & 68 & 37.4 \\
Firms ownership & 51 & 28.0 \\
Usage policies & 44 & 24.2 \\
Taxes for importing ICTs & 39 & 21.4 \\
\hline
\end{tabular}

Source: Field Data, 2017 
The outputs in Table 7 from a multiple linear regression analysis performed to test the impact of a firm's size and its materials' source on the usage of ICTs to boost business processes indicate that the factors' influences are statistically significant (i.e. $P$ value $<.05)$. This implies that the two factors strongly influence firms' usage of a wide range of ICTs to support different kinds of business processes. The other factors such as a firm's year of establishment, the nature of its business, its origin, its markets and location have been found to have statistically insignificant influences (i.e. $P$ value $>.05$ ) on the same. In other words, these factors do not have a direct influence on the usage of ICTs for business purposes.

\section{Barriers of deploying ICTs for business processes}

The firm' representatives were also asked to cite the challenges facing the usage of ICTs to support business processes in their firms. The results obtained tell that the firms are not resistant to challenges associated with the usage of these tools to support diverse business activities. Table 8 summarises the results:

The results summarised in Table 8 show that there are various barriers to effective usage of ICTs in business processes. It has been observed that more than half (62.8\%) of the firms' representatives found inadequate technological savvy as a barrier while $58.8 \%$ pointed out unfriendly regulatory frameworks, and 52.7\% cited financial constraints. Besides these, a moderate percentage (36.8\%) of the respondents reported ICTs security issues as deterrence to their effective usage in innovative activities. On the other hand, unreliable internet and other networks, and unstable power supply have been found to insignificantly hinder the usage of these tools in innovative business activities at the selected firms. In all, the results suggest that the usage of ICTs for business face both internal and external barriers. During one interview session, a key informant (i.e. no. 14) stated the following as a barrier for deploying ICTs in business processes:

Our firm's investment of a lot of money in the acquisition of sophisticated information and communication technologies is overshadowed by its lack of

Table 7 Multiple linear regression analysis

\begin{tabular}{|c|c|c|c|c|c|c|}
\hline \multirow[t]{2}{*}{ Model } & & \multicolumn{2}{|c|}{ Unstandardised coefficients } & \multirow{2}{*}{$\begin{array}{l}\text { Standardised } \\
\text { coefficients } \\
\text { Beta }\end{array}$} & \multirow[t]{2}{*}{$T$} & \multirow[t]{2}{*}{ Sig. } \\
\hline & & $B$ & Std. error & & & \\
\hline \multirow{10}{*}{$\begin{array}{l}\text { Determinants of wide } \\
\text { variety of ICT usage }\end{array}$} & (Constant) & 1.967 & .233 & & 8.458 & .000 \\
\hline & Year of establishment & .026 & .047 & .041 & .552 & .582 \\
\hline & Nature of business & .027 & .022 & .094 & 1.191 & .235 \\
\hline & Size of firms & -.298 & .043 & -.524 & -6.917 & .000 \\
\hline & Origin of the firm & .019 & .078 & .018 & .245 & .807 \\
\hline & Sources of materials & .312 & .029 & .691 & 9.152 & .000 \\
\hline & Markets & -.038 & .037 & -.074 & -1.016 & .311 \\
\hline & Location & .016 & .027 & .042 & .592 & .555 \\
\hline & (Constant) & 1.967 & .233 & & 8.458 & .000 \\
\hline & Year of establishment & .026 & .047 & .041 & .552 & .582 \\
\hline
\end{tabular}

Dependent variable: use of wide variety ICTs to enhance business processes Source: Field Data, 2017 
Table 8 Barriers of deploying ICTs for business processes

\begin{tabular}{|c|c|c|}
\hline \multirow[t]{2}{*}{ Challenges $(n=182)$} & \multicolumn{2}{|l|}{ Agree } \\
\hline & Frequency & Percent \\
\hline Inadequate technological savvy limits the application of ICTs in our firms & 114 & 62.8 \\
\hline Unfriendly regulatory frameworks deter effective usage of ICT to support innovation & 107 & 58.8 \\
\hline Financial constraints limit the accessibility and usability of ICTs & 96 & 52.7 \\
\hline Security issues deter the effective usage of ICTs & 67 & 36.8 \\
\hline Unreliable Internet and networks undermine the usage of ICTS & 51 & 28.0 \\
\hline Unreliable power supply is affects effective usage of ICTs & 44 & 24.2 \\
\hline
\end{tabular}

Source: Field Data, 2017

investment in staff training on the usage of the ITCs. The result of this has been a low return from the investments. For example, new employees are not oriented on the usage of different software acquired by the organization and as a result they do not use them. This poor prioritisation slows down the usage of the technologies for innovation [gender, female; age, 35; designation, managing director; business type, service; town, Tanga].

Another key informant (no.1) narrates that:

Technophobia is a common phenomenon in our firm. Due to lack of skills some staff members avoid using technologies to support their daily operations. Some of the reasons some of them avoiding the usage of technology are not clearly known. As it appears, their avoidance might be associated with negative attitudes, and lack of usage knowledge and skills among them. Despite undergoing some training on their usage, the innovative usage of these tools is still not promising [gender, male; age, 39; designation, director; business type, processing products; town, Mbeya].

On a similar note, informant no.15 had the following to say:

Some kinds of computerized systems are not user friendly; they require too much effort from users to operate such that if a user is not eager enough to learn they are less likely to go ahead. This is a common practice in majority of public organizations [gender, female; age, 48; designation, firm supervisor; business type, service; town, Mwanza].

In the same regards, key informant no. 11 added the following:

For our case, the main problem is the insufficiency of financial resources for acquiring modern ICT facilities. We know the opportunities these facilities offer but the capital to invest is the issue. That is mainly the reason there are less advanced or no ICTs infrastructure in other small firms like ours. As a result, mobile phones are the most important technologies that support our operations. Lucky enough every staff member as well as our clients has mobile phones. We use these to communicate with them through text messaging and WhatsApp which are important platforms for marketing our services and products [gender, female; age, 35; designation, managing director; business type, manufacturing; town, Tanga]. 
Apart from that, key informant no. 6 informs that:

In many circumstances, inadequate awareness among staff on the kinds of systems that would support the firm's performance and boost innovation are the barriers of effective usage of ICTs in our company. In addition to that, sometimes the technologies are accompanied by different supporting tools of which our staff members are not aware. Worse still, our staff members do not care to spend time to research on the kinds of supportive tools accompanying the technologies we have hence their underutilisation [gender, male; age, 58; designation, managing director; business type, product processing; town, Dar e Salaam].

In addition, key informant no. 6 disclosed that:

Low usage of ICTs to support diverse innovations is associated with the lack of policies. Based on my experience, most firms do not have frameworks to guide innovative deployment of ICTs in place. As a result, people use a trial and error model to accomplish the tasks assigned to them. Without legal and policy frameworks, our local firms cannot effectively compete with firms of foreign origin [gender, male; age, 54; designation, director; business type, service; town, Dar es Salaam].

From these narrations, it is worth noting that the usage of ICTs to support firms' innovation is surrounded by dissimilar challenges and problems. Basically, the findings indicate that the main challenges are associated with financial constraints, insufficiency of knowledge and skills, absence of policy and legal frameworks, inadequacy of ICT infrastructure and nature of technology.

\section{Discussion of the findings}

\section{Types of ICTs used in business processes}

The benefit of access to and deployment of ICTs is unquestionable for all firms regardless of their size, nature of business, location and origin. However, it is worthy pointing out that different types of ICTs seem to penetrate different firms in Tanzania at varying paces. As noted from these findings, the adoption and deployment of these tools to support firms' operations do not just vary based on firms but also on the types of ICTs. In all, mobile phones, computers, landline telephones, photocopiers, printers and Electronic Fiscal Device (EFD) machines have been found to be deployed by majority of firms. In addition to these, it has been found that some firms have subscribed to Internet services and have websites. On a different note, the findings have revealed that the extent of deployment of these tools (with the exception of mobile phone technology) by micro firms is not promising. This appears to be a common thing considering that other studies (e.g. Cirera et al., 2016; Franco \& Garcia, 2017) conducted elsewhere have revealed unsatisfactory deployment of ICTs by small firms as compared to medium and large ones. The discrepancies found across firms regarding the usage of different technologies also suggest that there is more usage of computers and Internet services in medium- and large-sized firms than in small ones.

Similarly, other studies (e.g. Apiyo \& Kiarie, 2018; Ssewanyama \& Busler, 2007) support that Internet and computers are highly deployed in medium and large firms. 
Another important finding to note from this study is the extent of mobile phone technology usage to support businesses processes in firms of all sizes on which a statistically insignificant difference has found across all firms. In fact, the tools have penetrated all types of firms where they support diverse business activities. The explanations for this are threefold: firstly, mobile phone prices are dwindling; secondly, the tools contain multiple useful functionalities; and finally, the technology is user friendly and easy to learn compared to computers which are more knowledge and skills demanding (Mwantimwa, 2019). When it comes to the most important ICTs in supporting diverse innovations; computers, mobile phones, and the Internet are highly rated by respondents while computer software and websites are moderately rated. This is an indication that not all types of ICTs are considered effective in fostering business efficiency. In a slight contrast, a study by OECD (2004) revealed that computers and the Internet are the most widespread technologies in all size of the firms. This could be attributed to the fact that the results are from developed countries where the situation is likely to be different from what exists in developing countries (see Cirera et al., 2016) such as Tanzania.

\section{Usage of ICT in business processes}

Information and communication technologies are believed to be part and parcel of the basic assets needed to succeed in business innovations. The findings of this study confirm this by revealing that ICTs' usage indeed enhances innovation. Predominantly, the technologies have been found to introduce new ways of communicating, order processing, handling money transactions, performing management duties and managing records and data. In particular, ICTs have improved how communication between firms and their clients, vendors, and among their staff is done. Undeniably, technologies such as mobile phones, emails and social media provide firms with an enhanced two-way communication model. On the same note, these technologies present firms with more innovative ways of creating information and knowledge for supporting their business. Similarly, findings of a study by Tahir and Sam (2010) revealed that knowledge made available with the help of ICTs increases business capabilities of firms.

Regarding financial transactions, the findings suggest that ICTs, especially mobile money services, have smoothened the flow of money. This is a very good development considering that, noting from personal experience, the risk of carrying large amounts of money in Tanzania is increasing. With the usage of technologies such as the Internet and mobile phones, one can pay utility bills and purchase products through mobile money and e-banking services. In addition, the technologies have been found to facilitate processes and transactions of B2B and B2C e-business models. Likewise, these technologies have been reported by other authors to offer a wide range of intrafirm business process and transactional benefits (see, OECD, 2004). In addition, technologies such as computers have been found to foster the creation of databases of clients contacts details, assets, employees profiles and projects on platforms such as Ms Access to support management activities.

Surprisingly, the study findings suggest that a variety of ICTs are moderately utilised in the processing products and services, marketing, receiving feedback from clients, preparing invoices and strengthening security. For example, the findings disclose that computers and software (e.g. Ms Publisher) are not optimally used to create promotion materials. This is so despite clear revelations that these tools present opportunities for coming up 
contemporary business processes (Jorgenson et al., 2011; Diaz-Chao, 2015) in areas such as packing of products (see also Idota et al., 2014). Similar unsatisfactory deployment of these tools in innovative business activities was observed by Cirera et al. (2016). In their usage of ICTs for marketing purposes, the firms involved in the study have been found to use social media to support promotion of their products and services.

Understandably, mobile phone technology is very prominent in the firms because it is the main driver for the increased usage of social media to support business operations particularly the promotion of products and services. Basing on the respondents' narrations, even small firms are taking advantages of mobile phone technology on which the potentials of platforms such as WhatsApp, Facebook, Twitter and Instagram are exploited innovatively. In particular, these social media platforms are playing a great role in positively influencing knowledge creation processes and fostering business processes (Papa et al., 2018; Mwantimwa, 2019). The platforms are quickly changing the model of marketing services and products and making it more affordable. The findings further disclose that the interactive nature of these technologies allows firms to receive feedback and product requests from clients. In all, the insignificant deployment of ICTs to support marketing activities has potential negative impact on firms' competitiveness and the economic development of the nation at large.

\section{Determinants of ICT usage in business processes}

In the today's business world, a firm's attempts at innovation of business processes without the support of necessary elements can be likened to trying to turn a wheel that lacks a lubricant. Firms that want to be innovative enough have to be ready to embrace ICTs. The findings of this study reveal a number of factors that determine a firm's ability to use these tools for business purposes. Basically, the observed heterogeneity on the usage of ICTs across firms of different sizes is influenced by determinants that predict the usage of the tool. Specifically, it has been further disclosed by this study that effective usage of these tools to boost business processes in Tanzania depends mainly on the availability of hardware, Internet, software, knowledge investments and network systems. Of course, these requirements depend on each to operate hence the need for the presence of most of them. For instance, a combination of hardware, software and knowledgeable staff is an enabling factor for fostering a variety of business processes.

Apart from that, the findings inform that the nature of business and size of firms, and the awareness of diverse ICT tools moderately determine the usage of these tools in innovative activities. In fact, the complexity of medium- and large-sized firms boosts the adoption and deployment of ICTs due to their ability to simplify the complex processes of managing them. Likewise, findings from a study by Gerguri-Rashiti et al. (2015) agree with this study's findings on the impact of a firm's size in determining the usage of ICTs in business. Moreover, the findings indicate that large- and medium-sized firms are more likely to deploy a wide variety of ICTs than small ones. In agreement, Grazzi and Jung (2015) and Cirera et al. (2016) insist that larger, older, skill intensive, export-oriented and urban-based firms are more likely to deploy ICTs for business. However, this study's findings from multiple linear regression analyses revealed that the location and age of a firm insignificantly explains the 
heterogeneity on the usage of ICTs across firms. In all, the findings confirm that the size of a firm, knowledge investments and source of raw materials determine the usage of ICTs for business processes.

On the other hand, the nature of a firm's ownership and ICTs' usage regulatory frameworks has been found to insignificantly determine the usage of these tools for business. Although the findings disclose an insignificant contribution of regulatory frameworks in the determination of ICTs' usage for business, Ssewanyama and Busler (2007) found them (e.g. policies on taxes, VAT) to strongly influence effective adoption and usage of these tools for business process innovation. These factors are believed to have an impact as strong as knowledge investments in boosting the usage of ICTs in innovative activities (Billon et al., 2017; Cirera et al., 2016). For example, large firms have an advantage of having more skilled staff capable of deploying ICTs for innovative purposes (Ssewanyama \& Busler, 2007).

In contrast, Franco and Garcia (2017) noted a statistically insignificant influence of experts and knowledgeable personnel on fostering business through the usage of ICTs. Furthermore, basing on multiple regression analysis, the findings suggest that firms' profile such as nature of business, size and sources of materials determine the usage of wide varieties of ICTs on business. From all these findings, it is worth noting that the usage of ICTs for innovation depends on both internal and external factors. All in all, financial resources have the power to determine the kinds of ICTs to adopt and use for business, a fact corroborated by Hadjimanolis (2000) who argues that financial power is an important predictor for the usage of ICTs in the development of innovative products and services.

\section{Barriers of ICT usage in business processes}

Although the findings disclose that firms have deployed ICTs for business, the trend of their usage for such purposes is not highly promising. This has been attributed to barriers such as inadequate knowledge, technophobia, unfriendly regulatory frameworks and financial constraints which limit the maximisation of technology usage to enhance business processes. As a result of these barriers, not all firms are taking advantage of these tools to embark on innovative projects (see also Gerguri-Rashiti et al., 2015). Apparently, despite large investment in broadband networks, low bandwidth and unreliable networking remain an issue. In addition to that, it has been reported that even firms that have invested on quality ICT facilities, their usage is undermined by factors such as the availability of ICT experts, politics and low financial capacity (Michael, 2015). In particular, insufficient investment in knowledge development has been found to significantly deter the effective usage of ICTs to support business, as does poor ICT infrastructure which affects competitive business innovations across sub-Saharan Africa (e.g. Cirera et al., 2016). For example, computers, software, and IT experts are found to be too expensive by small firms.

No wonder the level of ICT deployment varies across firms. Such uneven adoption and usage of these tools is also contributed to by unfriendly regulatory frameworks notably import taxes, VAT and business policies. These findings inform that import taxes and VAT associated with ICT facilities are unaffordable for some firms particularly small ones (Michael, 2015; Ssewanyama \& Busler, 2007). Similarly, some firms are discouraged by long procedures for importing ICT equipment (Michael, 2015). These issues are partly the reason 
small firms are very slow in adopting and applying computers and Internet services. Likewise, Franco and Garcia (2017) and Billon et al. (2017) argue that poor technological savvy and insufficient management and financial resources explain the low adoption and applications of ICTs. On the whole, and financial constraints appear to be the main barrier to firms' adoption and effective usage of ICTs for business processes in Tanzania.

\section{Theoretical and practical implications}

The present study contributes theoretically and practically. Its major contribution is increasing the understanding on how ICTs foster diverse business processes in firms. This is due to the fact that there is a dearth of information and knowledge on this area, specifically from studies that present comparative analysis across firms globally and in Tanzania in particular. This study, therefore, helps to fill gaps existing in empirical literature and provides new insights on the usage of ICTs to support diverse business processes. As such, the study's findings are likely to be an important resource for policy and strategy developers in their quest to create sustainable and competitive business environments. However, there are a number of questions that this study leaves unanswered, as well as a number of new ones it raises. In all, the study provides a foundation for future studies on the use of emerging ICTs such as mobile technologies, social media and web resources in business processes.

\section{Conclusion and recommendations}

Uneven computers and Internet services' access and usage to support diverse business processes across firms are well documented as confirmed by the reviewed literature sources. On the other hand, the support mobile phone technologies offer to business process is not well revealed in majority of the reviewed literature. With regard to that, this study informs that mobile phone technology is becoming more important in supporting various business processes across firms of all sizes. The tools are therefore lessening the technological gaps reported in other studies by allowing smaller firms (usually unable to afford expensive ICTs) to use them to support marketing, management activities and other processes. On top of that, mobile phone technology is an important driver in the fostering of social media platform usage in promotion activities. In addition, the penetration extent of the technology has made social media become fundamental in knowledge creation, management and dissemination, hence playing a great role in business processes. Evidently, ICTs in general (mobile phones and the Internet inclusive) are lessening the cost of managing businesses through their support of innovations in money transactions, online businesses, and knowledge creation and sharing.

In all, ICTs' usage to foster business processes in the firms that participated in this study is unquestionable and so is their effect on particular areas such as product development and marketing. However, it is worth noting that these tools are insignificantly deployed in the studied firms, a situation attributed to barriers such as poor ICT infrastructure. Furthermore, the findings reveal that the nature of firm ownership does not guarantee maximum exploitation of ICTs to enhance business processes, hence the need to avoid underestimating other determinants such as knowledge investments, regulatory frameworks, and ICT acceptance and motivation to use them. In summary, in order to make ICTs' usage in business processes meaningful, there are a number of 
things that need consideration. To start with, firms need to build capacity for their human resources so as to enable them to optimally utilise ICTs available to facilitate business activities. Secondly, the government has to create an ICT friendly environment by modifying the current restrictive regulatory frameworks. Apart from that, both business and the government should work towards improving infrastructure to support the usage of ICTs in business activities. Likewise, the effective adoption of social media to enhance business processes is to be considered by the firms of all size due to its cost-effectiveness and popularity.

\begin{abstract}
Abbreviations
B2B: Business-to-business; B2C: Business-to-consumers; DITF: Dar es Salaam International Trade Fair; EFD: Electronic Fiscal Device; GDP: Gross Domestic Product; IBM: International Business Machines; ICTs: Information and Communication Technologies; NSEGPR: National Strategy for Economic Growth and Poverty Reduction; OECD: Organization for Economic Co-operation and Development; SCM: Supply Chain Management; SPSS: Statistical Products for Service Solutions; URT: United Republic of Tanzania
\end{abstract}

\title{
Acknowledgements
}

The earlier version of the manuscript was presented at the 16th Globelics International Conference held in AcrraGhana on October 24-26 2018. The author acknowledges the contribution of anonymous reviewers, session chair, discussants, and other conference participants for enriching the article. Moreover, my heartfelt thanks go to the University of Dar es Salaam staff notably Mr. Elias Mwabungulu for his inputs and language expertise.

\section{Authors' contributions}

The manuscript is single authored. KM carried out the fieldwork, data analysis, and prepared the manuscript. The author read and approved the final manuscript.

\section{Funding}

The research was self-funded.

\section{Availability of data and materials}

Dataset used is available upon reasonable request from the author.

\section{Competing interests}

The author declares that he has no competing interests.

Received: 15 December 2018 Accepted: 9 July 2019

Published online: 22 July 2019

\section{References}

Apiyo, R. O., \& Kiarie, D. (2018). Role of ICT tools in supply chain performance. Internal Journal of Supply Chain Management, $3(1), 17-26$.

Arendt, L., \& Grabowski, W. (2018). Impact of ICT utilisation on innovations and on labour productive: micro-level analysis for Poland. Modelling Innovation Sustainability and Technologies, 225-247.

Barret, M., Davidson, E., Prabhu, J., \& Vargo, S. I. (2015). Service innovation in the digital age: key contributions and future directions. MIS Quarterly, 39(1), 135-154.

Bartelsman, E., Hasten, E., \& Polder, M. (2017). Micro moments database for cross-country analysis of ICT, innovation, and economic outcomes. Tinbergen Institute Discussion Paper, 2017-003/NI.

Billon, M., Marco, R., \& Lera-Lopez, F. (2017). Innovation and ICT use by firms and households in the EU: a multivariate analysis of regional disparities. Information Technology and People, 30(2), 424-448.

Burns, N., \& Grove, S. K. (2011). Understanding nursing research (5th ed.). Maryland: Saunders.

Cirera, X., Lage, F., \& Sabetti, L. (2016). ICT use, innovation, and productivity: evidence from sub-Saharan Africa. Policy Research Working Paper WPS 7868.

Diaz-Chao, A., Sainz-Gonzalez, J., \& Torrent-Sellens, J. (2015). ICT, innovation and firm productivity: new evidence from small local firms. Journal of Business Research, 68, 1439-1444.

Diyamett, B., Makundi, H., \& Mwantimwa, K. (2012). Impact of ICTs adoption and application on innovation in selected manufacturing firms in Tanzania, published by STIPRO.

Eze, S. C., \& Chinedu-Eze, V. C. (2018). Examining information and communication technology adoption in SMEs: a dynamic capabilities approach. Journal of Enterprise Information Management, 31(2), 338-356.

Franco, M. \& Garcia, M. (2017). Drivers of ICT acceptance and implementation in micro firms in the estate agent sector: influence on organizational performance. Information Technology for Development, 24(4), 658-680.

Gerguri-Rashiti, S., Ramadhani, V., Abazi-Alili, H., Leo-Paul, D., \& Ratten, V. (2015). ICT, innovation and firm performance: transition economies. https://doi.org/10.1002/tie.21772.

Grazzi, M., \& Jung, J. (2015). ICT, innovation and productivity: evidence from Latin American firms. IACEA.

Hadjimanolis, A. A. (2000). Resource based view of innovativeness in small firms. Technology Analysis and Strategic Management, 12(2), 263-281.

Hagsten, E., \& Kotnik, P. (2017). ICT as facilitator of internationalisation in small and medium sized firms, 48, 431-446. 
Idota, H., Ueki, Y., Bunno, T., Shinohara, S., \& Tsuji, M. (2014). Role of ICT in the innovation process based on firm-level evidence from ASEAN economies: an SEM approach. Brussels: Paper present in the 25th European Regional Conference of the International Telecommunications Society (IST).

Jackson, S. L. (2008). Research methods: a modular approach. Belmont: Thomson Wadsworth

Jorgenson, D.W., Ho, M.S., \& Samuels, J.D. (2011). Information technology and U.S. productivity growth: Evidence from a prototype industry production account. Journal of Productivity Analysis, 36 (2), 159-175.

Kossai, M., \& Piget, P. (2014). Adoption of information and communication technology and firm profitability: empirical evidence from Tunisian SMEs. Journal of High Technology Management Research, 25, 9-20.

Krone, M., Schumacher, K. P., \& Dannenberg, P. (2014). The impact of mobile phones on knowledge access and transfer of small-scale horticultural farmers in Tanzania. DIE ERDE-Journal of the Geographical Society of Berlin, 145(3), 158-161.

Michael, R. (2015). Analysis of challenges associated with adoption and diffusion of ICT: a case of Tanzania firms. Compusoft: An International Journal of Advanced Computer Technology, 4(8), 1952-1959.

Mwantimwa, K. (2012). The use of pull information mode to support poverty reduction programmes in rural Tanzania: a case of Monduli and Bagamoyo districts. PhD thesis: Universiteit Antwerpen.

Mwantimwa, K. (2018). Use of mobile phones in boosting socioeconomic information access and utilisation among Tanzania rural communities. African Journal of Library, Archives and Information Science, 28(1), 107-122.

Mwantimwa, K. (2019). Use of mobile phones among agro-pastoralist communities in Tanzania. Information Development, $35(2), 230-244$.

OECD \& Eurostat. (2005). Oslo Manual, Guidelines for collecting and interpreting innovation data. Paris: OECD.

Organisations for Economic Co-operation and Development [OECD]. (2004). ICT, e-business and SMEs. A paper presented in 2nd OECD conference of ministers responsible for small and medium sized enterprises (SMEs). Promoting enterpreneurship and innovative SMEs in global economy: towards a more responsible and inclusive globalisation 3-5 June, 2004.

Papa, A., Santoro, G., Tiraben, L., \& Monge, F. (2018). Social media as tool for facilitating knowledge creation and innovation in small and medium enterprises. Baltic Journal of Management, 13(3), 329-344.

Rutageruka, E. (2017). The 40th DITF exhibition catalogue: linking production to markets. https://dokumen.site/download/4 Oth-ditf-catalogue-2016-a5b39fofd67012

Southern, A., \& Tilley, F. (2000). Small firms and information and communication technologies (ICTs): toward a typology of ICTs usage. New Technology, Work and Employment, 15(2), 138-154.

Sreejesh, S., Sanjay, M., \& Anusree, M. R. (2014). Business research methods: an applied orientation. New York: Springer.

Ssewanyama, J., \& Busler, M. (2007). Adoption and usage of ICT in developing countries: case of Ugandan firms.

Tahir, N. H., \& Sam, M. F. (2010). Innovation activities in the Malaysian public sector: factors promoting the by product of ICT usage. IJRRAS, 2(3), 296-305.

The Tanzania Trade Development Authority [TANTRADE]. (2017). Exhibitors for Dar es Salaam International Trade Fair. Dar es Salaam.

United Republic of Tanzania. (2016). National Information and Communication Technology Policy. Dar es Salaam: Ministry of Works, Transport and Communication.

URT (2005). National Strategy for Growth and Reduction of Poverty (NSGRP), Dar es Salaam: Vice President's Office.

Wolf, S. (2001). Determinants and impact of ICT use for African SMEs: implications for rural South Africa. TIPS Forum.

\section{Publisher's Note}

Springer Nature remains neutral with regard to jurisdictional claims in published maps and institutional affiliations.

\section{Submit your manuscript to a SpringerOpen ${ }^{\circ}$ journal and benefit from:}

- Convenient online submission

- Rigorous peer review

- Open access: articles freely available online

High visibility within the field

Retaining the copyright to your article

Submit your next manuscript at $\boldsymbol{\sim}$ springeropen.com 